\title{
Recent advances in regulation of flowering
}

\section{Julin N Maloof}

Address: Department of Plant Biology, University of California, Davis, 1 Shields Avenue, Davis, CA 95616, USA

Email: jnmaloof@ucdavis.edu

FI000 Biology Reports 2010, 2:9 (doi:10.34I0/B2-9)

The electronic version of this article is the complete one and can be found at: http://f1000.com/reports/biology/content2/9

\begin{abstract}
The control of flowering time in plants is critical for plant fitness and for agriculture. The genetic pathways governing this developmental transition are reasonably well understood in Arabidopsis, although substantial new gains are still being made in this system. Much new work is focusing on how the genetic networks governing flowering function in other species.
\end{abstract}

\section{Introduction and context}

The switch from vegetative to reproductive growth in angiosperms is a major developmental transition, an important determinant of life history, and a critical component of fitness (e.g., [1-3]). To maximize seed production, flowering must be coordinated with internal physiological and external environmental factors. Reproduction is energy-intensive and so should begin only when sufficient resources (stored starch or photosynthetic capacity) have accumulated and when environmental conditions will support continued growth through fruit production. Outcrossing plants will be successful only if neighbors flower at the same time, and animal-pollinated plants must time flowering to coincide with pollinator presence.

Given these constraints, it is no surprise that flowering time is tightly regulated and that there are many different strategies to control reproductive timing. Many plants are photoperiodic, with short-day plants (SDPs) and long-day plants (LDPs) flowering when days are shorter or longer than a critical photoperiod, respectively. Daylength is determined by an external coincidence system in which an external cue is compared with an internal oscillation. For example, in the LDP Arabidopsis, the circadian clock causes expression of CONSTANS (CO) mRNA to begin increasing approximately 12 hours after dawn. If there is a coincidence between light and high $C O$ transcripts, then CO protein is stabilized, leading to activation of FLOWERING LOCUS T (FT) transcription and synthesis of FT protein that acts as a mobile signal (a florigen) to induce flowering [4-6]. $C O$ and FT also are important for photoperiod sensing and response in the SDP rice, but $\mathrm{CO}$ action has been modified so that it functions as a repressor of flowering in the presence of light (there are a number of other important differences as well) $[7,8]$.

While the daylength may exceed the critical LDP photoperiod from spring through fall, fall may not be an appropriate period to flower. For example, if Arabidopsis plants germinating in early fall were induced to flower by the still relatively long days, they might not have time to produce mature seed before winter. Many plants have an additional system to help distinguish spring from fall: they require exposure to the prolonged periods of cold in winter before being responsive to inductive photoperiods. In Arabidopsis accessions that require vernalization, the MADS (MCM1, AGAMOUS, DEFICIENS, and SERUM RESPONSE FACTOR) domain transcription factor FLC (FLOWERING LOCUS C) is expressed strongly and represses flowering [9]. Prolonged exposure to cold causes stable downregulation of FLC through chromatin modification, and the plants are competent to respond to inductive photoperiods in the spring. Such vernalizationrequiring accessions have been thought to be 'winter annuals', germinating in the fall, overwintering as rosettes, and flowering in the spring. Accessions with mutations in FLC or its activator FRI (FRIGADA) are rapid cyclers not requiring vernalization. Surprisingly, the mechanisms controlling vernalization in winter wheat and barley 
appear very different from those of Arabidopsis. In these cereals, homologs of the Arabidopsis floral meristem identity gene APETALA 1 (AP1) and the florigen FT are critical for vernalization [10]. Finally, the gibberellin and autonomous pathways are important for promoting Arabidopsis flowering in the absence of photoperiodic induction $[11,12]$.

\section{Major recent advances}

I will focus on recent advances in two general areas: (a) refinement and surprises in Arabidopsis flowering control and (b) conservation and modification of the Arabidopsis pathway in other species. Given the extent of research on Arabidopsis flowering time, one might have thought that the major modes of regulation were known; however, recent research has revealed a new autonomous pathway. The SQUAMOSA PROMOTER-BINDING-LIKE (SPL) genes are known to affect flowering, with expression studies suggesting that they act downstream of CO and FT in photoperiodic flowering induction $[13,14]$. Recently, it was found that these genes are targeted by microRNA miR156 and that SPL expression increases over time concomitantly with a gradual decrease in miR156 expression [15,16]. Wang and colleagues [16] investigated miR156 expression and found that it was independent of gibberellins, vernalization, and CO and FT. While SPL expression can be induced by the photoperiodic pathway, the gradual increase is independent of FT, its homolog TSF (TWIN SISTER OF FT), and photoperiodic induction. This suggested the possibility that miR156 regulation of SPL could function as an autonomous inducer of flowering. Indeed, overexpression of miR156 delayed flowering in the absence of photoperiodic induction. This and subsequent experiments led to the conclusion that in addition to their role in photoperiodism, SPL genes define an autonomous pathway that can induce flowering through activation of the floral promoting MADS box genes SOC1 (SUPPRESSOR OF OVEREXPRESSION OF CONSTANS 1) and FUL (FRUITFULL) [16]. Additional studies place SPL3 upstream of floral meristem identity genes LFY (LEAFY) and AP1 [14].

MicroRNAs have also been shown to be important for regulation of the photoperiodic pathway [17]. Mathieu and colleagues [18] found that SCHLAFMÜTZE (SMZ), an AP2-like transcription factor, is a repressor of flowering in long days. SMZ function appears to overlap with that of other family members, so the effects of $s m z$ knockout mutants are most readily seen in multiple-mutant combinations. Chromatin immunoprecipitation suggests that $\mathrm{SMZ}$ functions by direct repression of FT. SMZ is targeted by miR172, and overexpression of a cleavageresistant $S M Z$ gene resulted in a complete failure of flowering.
Additional refinement to the photoperiodic pathway comes from Fornara and colleagues [19], who found that multiple DOF (DNA-binding with one finger) transcription factors redundantly repress $\mathrm{CO}$ expression. Previous work had shown that one DOF, CYCLING DOF FACTOR 1 (CDF1), represses CO expression and is targeted for degradation in long days by the FKF1 (Flavin-binding, Kelch repeat, F-box 1) photoreceptor complexed with GIGANTEA (GI) [20,21]. However, CDF1 knockdowns have only a small effect on flowering, suggesting redundancy. When the activity of four CDFs is reduced or eliminated, plants are aphotoperiodic and flower early in both short and long days [19]. Surprisingly, although gi mutants are late-flowering in long days, combining $g i$ with the four $c d f$ mutations restores near wild-type photoperiodism and cycling of CO transcript [19]. This result illustrates the multiple layers of regulation that exist, presumably to ensure proper flowering in the complex natural environment.

Most of what is known about the control of flowering in Arabidopsis comes from plants grown in controlled environment chambers. One of the most important papers published in the last year examined known Arabidopsis flowering mutants in the field [22]. Representative mutants from the photoperiodic, vernalization, and FVE/LD autonomous pathway were planted across the native European range of Arabidopsis in spring, summer, and fall cohorts timed to match germination of local populations. Surprisingly, in many environments/cohort combinations, lines expected to require vernalization did not exhibit winter annual behavior; instead, they flowered only marginally later than plants without an active vernalization pathway. This contrasts with expectations from growth chamber experiments that vernalization-sensitive plants would flower much later than 'rapid cyclers' in most circumstances. Thus, vernalization requirements can be met even in summer, perhaps by repeated exposure to cool evening temperatures. Wilczek and colleagues [22] developed a predictive model based on their results. In their modified photothermal model, plants are predicted to flower after accumulating a threshold amount of photothermal units. While such models have been used for years, the model here was extended by using prior information about the genetic differences between lines to individually scale the photothermal accumulation rate. Excitingly, this model was able to accurately predict flowering behavior in both new field and chamber plantings. Thus, the combination of detailed reductionist characterization of mutants in chambers followed by the field evaluation and modeling led to a new understanding of flowering behavior. 
Several recent papers have examined variation in the flowering pathway in different species. While Arabidopsis thaliana is an annual plant that flowers once and then senesces, the related species Arabidopsis alpina is a vernalization-requiring perennial that flowers yearly after exposure to cold [23]. How does vernalization work in this perennial? In A. thaliana, epigenetic modification stably represses FLC after cold exposure for the duration of the plant's life [9]; clearly, this system must work differently in A. alpina to allow it to respond to vernalization yearly. Wang and colleagues [23] screened mutagenized A. alpina and looked for mutants that no longer required vernalization. The perpetual flowering 1 (pep1) mutant was found to flower without vernalization, to flower continuously instead of reverting to vegetative growth, and to have fewer vegetative branches. Cloning revealed PEP1 to be an ortholog of FLC. What has changed to allow PEP1/FLC to function differently in this perennial plant? Unlike FLC, PEP1 is only transiently repressed in response to cold temperatures, allowing it to promote vegetative development until the following year.

To examine the genetic architecture and enable cloning loci for flowering variation (and other traits) in maize, Buckler and colleagues [24,25] created a large NAM (nested association mapping) population that captures much of the maize genetic diversity. Analysis of flowering revealed that in spite of large differences in parental flowering times, there are no large-effect QTLs (quantitative trait loci) segregating [26]. Instead, variation arises from the combined action of many small-effect loci with relatively little epistasis or gene-environment $(G \times E)$ effects. These findings differ substantially from the genetic architecture of flowering in Arabidopsis and rice, both of which harbor large-effect, environmentally sensitive loci [27-31]. An interesting possibility is that that these differences are due to different selective constraints in the outcrossing maize - where flowering within populations must occur simultaneously as compared with selfing Arabidopsis and rice, which (with regard to mating) would be tolerant of large changes in flowering time.

\section{Future directions}

A major future direction in understanding flowering will be increased comparative analyses. The current revolution in high-throughput sequencing is enabling experiments not possible 5 years ago and is opening up many more species to detailed comparative analyses - a theme in evidence at a past Keystone Symposium [32]. Specific to the studies discussed above, miR156 is present in monocots as well as dicots, but is its function in flowering conserved? Are changes in FLC regulation behind annual/perennial differences in many species? Is stable epigenetic modification of FLC common or specific to A. thaliana? Finally, to what extent do mating and life history strategies influence standing genetic variation present for these traits? We are lucky to be doing research at a time when answering these questions is within our grasp!

\section{Abbreviations}

AP1, APETALA 1; CDF1, CYCLING DOF FACTOR 1; CO, CONSTANS; DOF, DNA-binding with one finger; FLC, FLOWERING LOCUS C; FT, FLOWERING LOCUS T; GI, GIGANTEA; LDP, long-day plant; MADS, MCM1, AGAMOUS, DEFICIENS, and SERUM RESPONSE FACTOR; PEP1, PERPETUAL FLOWERING 1; SDP, short-day plant; SMZ, SCHLAFMÜTZE; SPL, SQUAMOSA PROMOTERBINDING-LIKE.

\section{Competing interests}

The author declares that he has no competing interests.

\section{Acknowledgments}

Work in the Maloof Lab is funded by National Science Foundation grant DBI-08-20854.

\section{References}

I. Sandring S, Agren J: Pollinator-mediated selection on floral display and flowering time in the perennial herb Arabidopsis lyrata. Evolution 2009, 63:1292-300.

2. Korves TM, Schmid KJ, Caicedo AL, Mays C, Stinchcombe JR, Purugganan MD, Schmitt J: Fitness effects associated with the major flowering time gene FRIGIDA in Arabidopsis thaliana in the field. Am Nat 2007, I69:EI4I-EI57.

3. Hall MC, Willis $\mathrm{JH}$ : Divergent selection on flowering time contributes to local adaptation in Mimulus guttatus populations. Evolution 2006, 60:2466-77.

4. Yanovsky MJ, Kay SA: Molecular basis of seasonal time measurement in Arabidopsis. Nature 2002, 419:308-I2.

FI000 Factor 6.0 Must Read

Evaluated by Richard M Amasino 25 Sep 2002

5. Suárez-López $P$, Wheatley $K$, Robson $F$, Onouchi $H$, Valverde $F$, Coupland G: CONSTANS mediates between the circadian clock and the control of flowering in Arabidopsis. Nature 200I, 4 I 0: I I I6-20.

FI000 Factor 6.0 Must Read

Evaluated by Richard M Amasino 12 Oct 200I

6. Turck F, Fornara F, Coupland G: Regulation and identity of florigen: FLOWERING LOCUS T moves center stage. Annu Rev Plant Biol 2008, 59:573-94.

7. Izawa T: Daylength measurements by rice plants in photoperiodic short-day flowering. Int Rev Cytol 2007, 256:19|-222.

8. Tamaki S, Matsuo S, Wong HL, Yokoi S, Shimamoto K: Hd3a protein is a mobile flowering signal in rice. Science 2007, 3 16:1033-6.

FI000 Factor 3.0 Recommended Evaluated by Daniel Gallie 13 Jun 2007

9. Sung S, Amasino RM: Remembering winter: toward a molecular understanding of vernalization. Annu Rev Plant Biol 2005, 56: 49I-508. 
10. Distelfeld A, Li C, Dubcovsky J: Regulation of flowering in temperate cereals. Curr Opin Plant Biol 2009, 12: 178-84.

II. Simpson GG: The autonomous pathway: epigenetic and posttranscriptional gene regulation in the control of Arabidopsis flowering time. Curr Opin Plant Biol 2004, 7:570-4.

12. Mutasa-Göttgens E, Hedden P: Gibberellin as a factor in floral regulatory networks. J Exp Bot 2009, 60:1979-89.

13. Schmid M, Uhlenhaut NH, Godard F, Demar M, Bressan R, Weigel D, Lohmann JU: Dissection of floral induction pathways using global expression analysis. Development 2003, I30:600I-I2.

FI000 Factor 3.0 Recommended

Evaluated by Richard Macknight 07 Nov 2003

14. Yamaguchi A, Wu MF, Yang L, Wu G, Poethig RS, Wagner D: The microRNA-regulated SBP-Box transcription factor SPL3 is a direct upstream activator of LEAFY, FRUITFULL, and APETALAI. Dev Cell 2009, 17:268-78.

FI000 Factor 6.0 Must Read

Evaluated by Martin Robert McAinsh 28 Aug 2009

15. Wang JW, Schwab R, Czech B, Mica E, Weigel D: Dual effects of miR I 56-targeted SPL genes and CYP78A5/KLUH on plastochron length and organ size in Arabidopsis thaliana. Plant Cell 2008, 20: $|23|-43$.

FI000 Factor 6.0 Must Read

Evaluated by Kay Schneitz 28 May 2008

16. Wang JW, Czech B, Weigel D: miR I56-regulated SPL transcription factors define an endogenous flowering pathway in Arabidopsis thaliana. Cell 2009, I38:738-49.

17. Jung JH, Seo YH, Seo PJ, Reyes JL, Yun J, Chua NH, Park CM: The GIGANTEA-regulated microRNAI 72 mediates photoperiodic flowering independent of CONSTANS in Arabidopsis. Plant Cell 2007, 19:2736-48.

FI000 Factor 6.0 Must Read

Evaluated by Elizabeth Dennis 04 Oct 2007

18. Mathieu J, Yant LJ, Mürdter F, Küttner F, Schmid M: Repression of flowering by the miRI72 target SMZ. PLOS Biol 2009, 7: el000I48.

19. Fornara F, Panigrahi KC, Gissot L, Sauerbrunn N, Rühl M, Jarillo JA, Coupland G: Arabidopsis DOF transcription factors act redundantly to reduce CONSTANS expression and are essential for a photoperiodic flowering response. Dev Cell 2009, I7:75-86.

20. Sawa M, Nusinow DA, Kay SA, Imaizumi T: FKFI and GIGANTEA complex formation is required for day-length measurement in Arabidopsis. Science 2007, 318:261-5.

21. Imaizumi T, Schultz TF, Harmon FG, Ho LA, Kay SA: FKFI F-box protein mediates cyclic degradation of a repressor of CONSTANS in Arabidopsis. Science 2005, 309:293-7.

FI000 Factor 4.9 Must Read

Evaluated by Tai-ping Sun 26 Jul 2005, Richard M Amasino 26 Jul 2005, Judy Callis 03 Aug 2005

22. Wilczek AM, Roe JL, Knapp MC, Cooper MD, Lopez-Gallego C, Martin LJ, Muir CD, Sim S, Walker A, Anderson J, Egan JF, Moyers BT, Petipas R, Giakountis A, Charbit E, Coupland G, Welch SM, Schmitt J: Effects of genetic perturbation on seasonal life history plasticity. Science 2009, 323:930-4.

FI000 Factor 6.4 Must Read

Evaluated by Julin Maloof 18 Feb 2009, Akiko Satake 09 Mar 2009
23. Wang R, Farrona S, Vincent C, Joecker A, Schoof H, Turck F, AlonsoBlanco C, Coupland G, Albani MC: PEPI regulates perennial flowering in Arabis alpina. Nature 2009, 459:423-7.

FI000 Factor 6.4 Must Read

Evaluated by Julin Maloof 07 May 2009, Ilha Lee 15 May 2009

24. McMullen MD, Kresovich S, Villeda HS, Bradbury P, Li H, Sun Q, FlintGarcia S, Thornsberry J, Acharya C, Bottoms C, Brown P, Browne C, Eller M, Guill K, Harjes C, Kroon D, Lepak N, Mitchell SE, Peterson B, Pressoir G, Romero S, Oropeza Rosas M, Salvo S, Yates H, Hanson M, Jones E, Smith S, Glaubitz JC, Goodman M, Ware D, et al.: Genetic properties of the maize nested association mapping population. Science 2009, 325:737-40.

FI000 Factor 6.0 Must Read

Evaluated by Brandon Gaut 16 Sep 2009

25. Yu J, Holland JB, McMullen MD, Buckler ES: Genetic design and statistical power of nested association mapping in maize. Genetics 2008, 178:539-5I.

26. Buckler ES, Holland JB, Bradbury PJ, Acharya CB, Brown PJ, Browne C, Ersoz E, Flint-Garcia S, Garcia A, Glaubitz JC, Goodman MM, Harjes C, Guill K, Kroon DE, Larsson S, Lepak NK, Li H, Mitchell SE, Pressoir G, Peiffer JA, Rosas MO, Rocheford TR, Romay MC, Romero S, Salvo S, Sanchez Villeda H, da Silva HS, Sun Q, Tian F, Upadyayula N, et al.: The genetic architecture of maize flowering time. Science 2009, 325:7|4-8.

FI000 Factor 6.4 Must Read

Evaluated by Magnus Nordborg 08 Oct 2009, Tony Long 15 Oct 2009

27. Zhao K, Aranzana MJ, Kim S, Lister C, Shindo C, Tang C, Toomajian C, Zheng H, Dean C, Marjoram P, Nordborg M: An Arabidopsis example of association mapping in structured samples. PLoS Genet 2007, 3:e4.

28. Shindo C, Aranzana MJ, Lister C, Baxter C, Nicholls C, Nordborg M, Dean C: Role of FRIGIDA and FLOWERING LOCUS C in determining variation in flowering time of Arabidopsis. Plant Physiol 2005, I38: I |63-73.

FI000 Factor 3.0 Recommended

Evaluated by Michael Lenhard 05 Jul 2005

29. Aranzana MJ, Kim S, Zhao K, Bakker E, Horton M, Jakob K, Lister C Molitor J, Shindo C, Tang C, Toomajian C, Traw B, Zheng H, Bergelson J, Dean C, Marjoram P, Nordborg M: Genome-wide association mapping in Arabidopsis identifies previously known flowering time and pathogen resistance genes. PLoS Genet 2005, I:e60.

F1000 Factor 6.0 Must Read Evaluated by JS Heslop-Harrison I 3 Dec 2005

30. Yano M, Katayose $\mathrm{Y}$, Ashikari M, Yamanouchi U, Monna L, Fuse T, Baba T, Yamamoto K, Umehara Y, Nagamura Y, Sasaki T: HdI, a major photoperiod sensitivity quantitative trait locus in rice, is closely related to the Arabidopsis flowering time gene CONSTANS. Plant Cell 2000, I 2:2473-84.

31. Izawa T: Adaptation of flowering-time by natural and artificial selection in Arabidopsis and rice. J Exp Bot 2007, 58:309|-7.

32. Jiménez-Gómez JM, Maloof JN: Plant research accelerates along the (bio)informatics superhighway: symposium on plant sensing, response and adaptation to the environment. $E M B O$ Rep 2009, 10:568-72. 